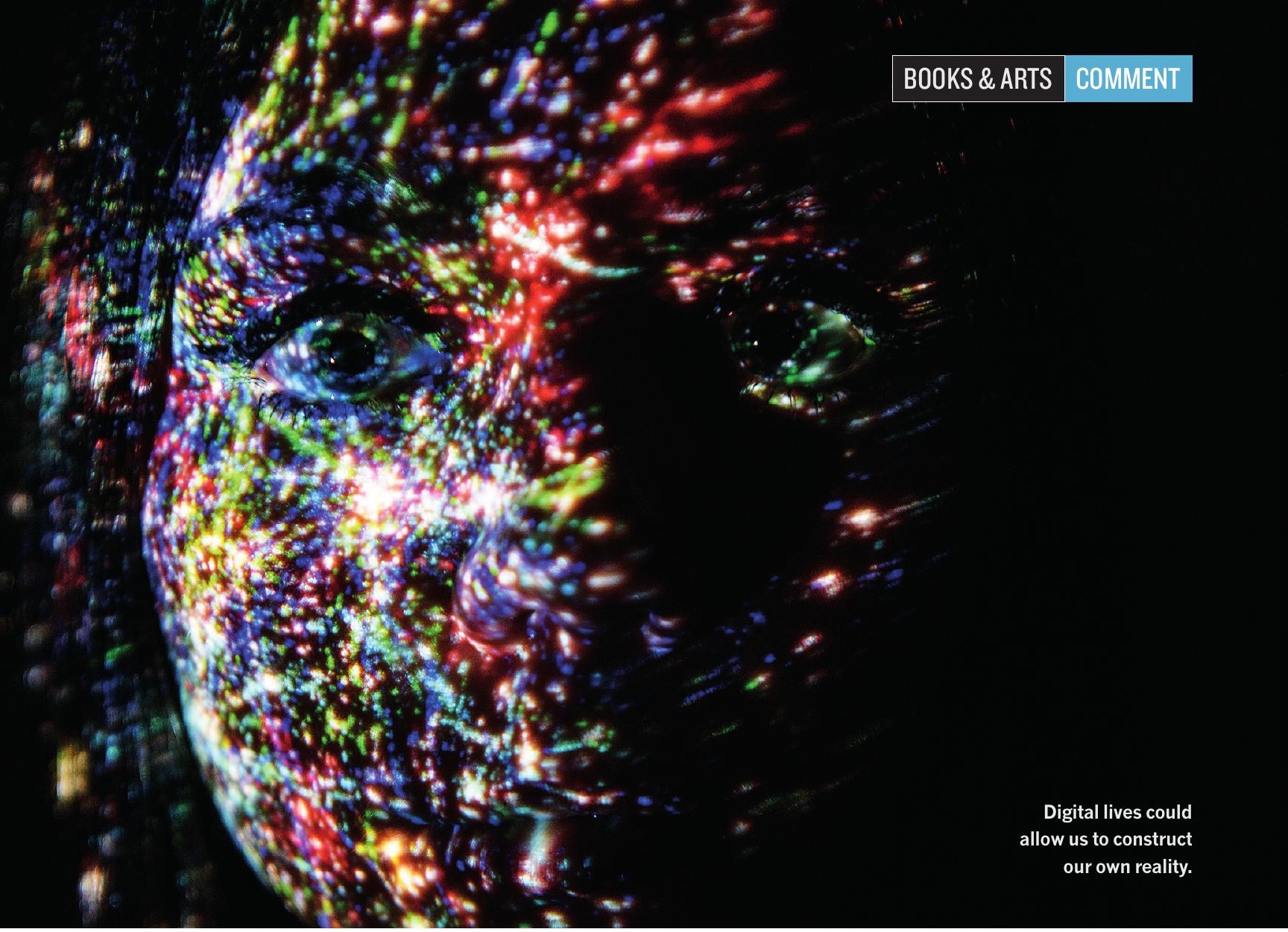

FICTION

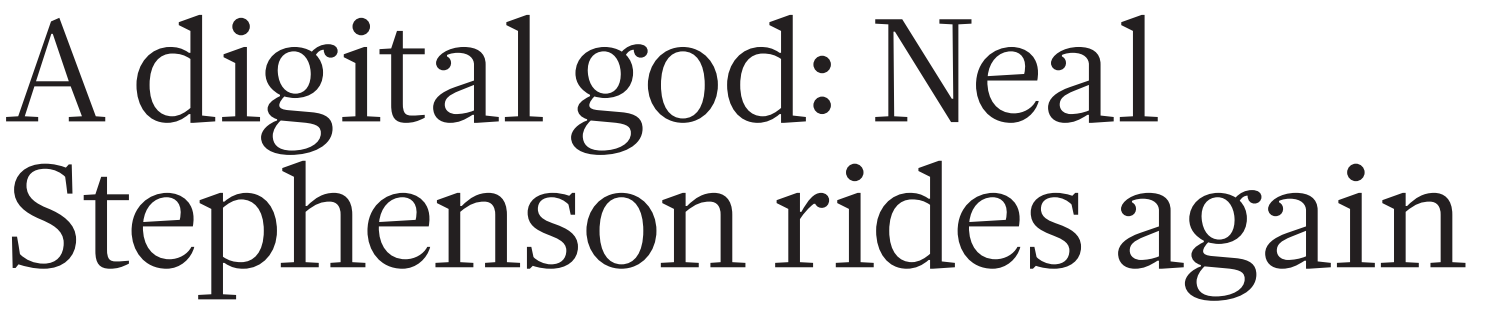

Heaven is in the Cloud in the prolific science-fiction writer's new tome.

Paul McEuen watches in wonder.

$\mathrm{N}$

eal Stephenson likes to blow things up. In Seveneves (2015), for instance, the prolific science-fiction writer detonated the Moon, then played out how humanity tried to save itself from extinction. In his new tome, Fall, the metaphorical explosion kills just one man. But this is an individual sitting on a few billion dollars, and longing to escape the shackles of mortality. The aftermath of the blast is thus just as powerful, and changes the fate of humanity just as profoundly.

The book's billionaire protagonist is Richard 'Dodge' Forthrast, a tech-head in Seattle, Washington, who made his wealth creating an online multiplayer universe called T'Rain. T'Rain is played by millions - and in gamer geekdom, Dodge is a rock star. But he is a thoughtful guy with a complex past, much of it detailed in Stephenson's 2011 novel REAMDE (see J. Gilbey Nature 478, 317; 2011).
Fall starts with Dodge preparing for an unnamed routine medical procedure. As the morning unspools, he notices a pair of books on Greek and Norse myths left behind by his grandniece, Sophia. At his favourite bakery, the owner presents him with a near-perfect apple. He collects a brilliant red maple leaf on his walk to the hospital. (These newly formed memories later take on greater significance.) At the hospital, he signs an autograph for a kid, who records it and posts it on the web.

That becomes the last record of the living Dodge. The procedure goes spectacularly awry, and he dies. Almost. His body is medically kept alive, because his will stipulates that his brain be preserved until technology is capable of regenerating it. This might not lead anywhere beyond a disembodied head on ice, joining the likes of psychologist James Bedford - were it not for the billions in Dodge's bank account, managed by his executor and former employee Corvallis Kawasaki. (Corvallis, from the Latin for crow, denotes intelligence and inscrutability. Names map characters in Fall; Stephenson has a lot of balls in the air, so he gives you many digital tags to keep track of them.)

Fast forward 20 years, and Dodge's billions have funded the technology to reboot him, although not in the way he envisioned: he is rebuilt, virtually. His brain is scanned atom by atom to create a 'connectome' - a wiring diagram for all his neurons - giving Stephenson the chance to geek out on neuroscience, focused ion beams and $>$ 
distributed quantum-computing technology.

Sophia, now an intern at a foundation created after Dodge's death, launches the brain simulation. That, in turn, gives birth to a new digital universe that expands in ways no one could have predicted.

As its god, Dodge recreates himself out of the nothingness of the digital void before building a virtual cosmos (as a video-game designer, he knows the ropes). Others join him as they die and are scanned, leaving "Meatspace" (the world of the living) behind. There are twists and turns, and many mythic tales and conflicts are re-enacted.

Much of the focus remains on Meatspace and the challenges faced by those left behind to maintain and understand the workings of the digital heaven they've created. This is one of the most interesting aspects of Fall. Their tools for seeing into it are imperfect, monitoring the communication between the various sub-processes distributed across a network of computing platforms (yes, Heaven is in the Cloud). Ultimately, they become obsessed with Dodge's constructed reality and it becomes a kind of Truman Show, where you can join the cast if you're rich enough to be scanned and are willing to die.

Fall is a doorstop. At almost 900 pages, Stephenson takes his time in laying out the story. It's a mash-up of fantasy and sci-fi, with some flavour of J. R. R. Tolkien and William Gibson, and the author is not afraid to go off on tangents that don't advance his tale.

Yet I got the impression that Stephenson, who has moonlighted for tech start-ups such as Blue Origin in Kent, Washington, and the Florida-based Magic Leap, doesn't really care what we think. Writing is an act of exploration and creation, a journey to a new world. That someone will later read what was written is arguably irrelevant; the dead in Fall, after all, live out their second lives in the digital realm unconcerned about observers, having left that inferior world behind.

Like Dodge, Stephenson is creating a new universe from scratch, fighting battles and wrestling with big ideas. Those of us in Meatspace can only sit mutely by and watch the spectacle in wonder.

Paul McEuen is a physicist at Cornell University in Ithaca, New York, and director of the Kavli Institute at Cornell for Nanoscale Science. His novel Spiral won debut of the year from the International Thriller Writers Association. He's hard at work on his next novel, The Long Echo.

e-mail:plm23@cornell.edu

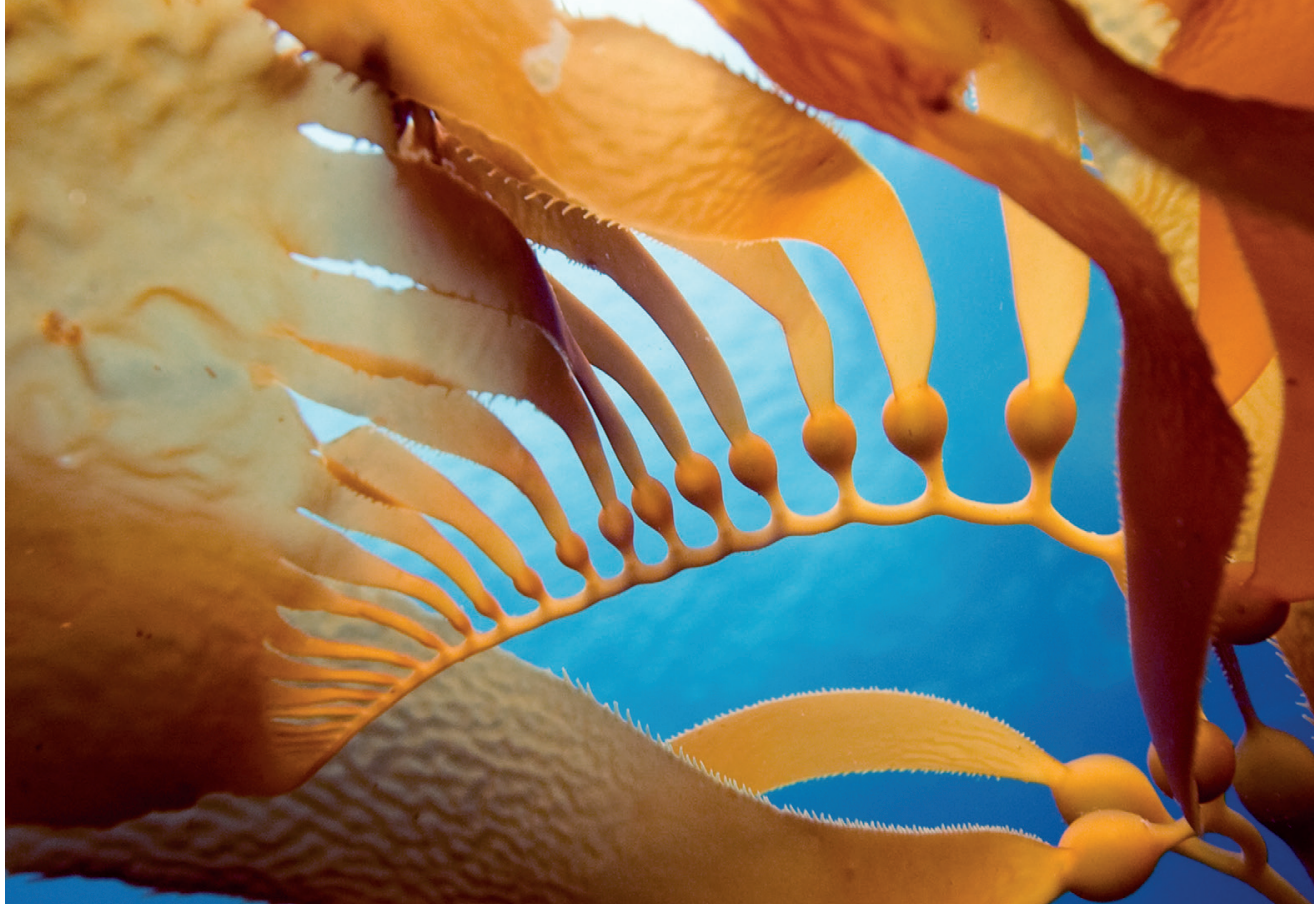

Kelp, a type of brown alga, growing off the coast of California.

\title{
PHYCOLOGY
}

\section{A brief history of slime}

\author{
Christopher Howe delights in a new book on the \\ planet's most powerful organisms - algae.
}

I rankles when I hear a distinguished molecular biologist declare that this gene or that 'is conserved throughout eukaryotes, from yeast to humans'. Yeast and humans (plus nematodes, zebrafish and many other organisms) are not representative of all eukaryotes, which have nuclei and membranebound organelles in their cells. They

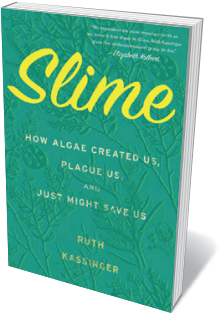

Slime: How Algae Created Us,

Plague Us, and Just Might Save Us RUTH KASSINGER Houghton Mifflin Harcourt (2019) belong to one rather restricted evolutionary group, the Opisthokonta (see S. M. Adl et al. J. Eukaryot. Microbiol. 66, 4-119; 2019), and account for a tiny fraction of global biomass (see Y. M. Bar-On et al. Proc. Natl Acad. Sci. USA 115, 6506-6511;2018).

So it is a real pleasure to see Slime (sold as Bloom in some territories), a book devoted to algae: the often-neglected eukaryotes and prokaryotes (organisms without nuclei or discrete organelles) that are of immense biological importance, yet only distantly related to yeast and humans.

Science writer Ruth Kassinger, who specializes in botany, covers the entire range of algae. They include blue-green algae (the oxygenproducing, photosynthetic cyanobacteria), red and green algae (close relatives of land plants), and distantly related groups such as diatoms, coccolithophores (responsible for chalk deposits such as the White Cliffs of Dover), dinoflagellates and kelp. Kassinger rightly describes algae as "the most powerful organisms on the planet" - not least for the amount of carbon dioxide they 'fix', or turn into organic matter. She sets out to educate us on their importance and compelling interest.

Slime has four parts. One concerns evolution, including how algae determined the growth of Earth's atmosphere. The second is on algae as food. The third covers cultivation for uses from sports shoes to fuel. And the last looks at human impacts, from coral bleaching to eutrophication, and how algae might redress the effects. There is also a fascinating appendix of recipes using algae. (I'm eagerly awaiting delivery of 'Irish moss', the red alga Chondrus crispus, to make blancmange.)

The smallest algae are single-celled prokaryotes less than a micrometre across, such as the oceanic Prochlorococcus, a major player in $\mathrm{CO}_{2}$ fixation. Others range from unicellular eukaryotes to multicellular seaweeds many metres long. They grow in environments from polar snow to hot springs.

Some have lost the ability to photosynthesize and now live as parasites. The most notorious is Plasmodium, arguably the most dangerous alga in the world, which retains a remnant, non-photosynthetic chloroplast and is the cause of malaria.

In spite of having studied algae for more than 30 years, I learnt much from Slime. I 